\title{
Candidaturas independientes: una nueva figura en México
}

\section{Independent Candidacies: a new option in Mexico}

\author{
Gema Morales Martínez
}

Recepción: 02 de mayo de 2018

Aceptación: 02 de octubre de 2018

Resumen

Las candidaturas independientes son consideradas una nueva figura en México ya que se vuelven una realidad palpable a partir de la reforma político electoral puesta en marcha en 2014. Sin embargo, le anteceden una serie de acontecimientos que derivaron en dicha reforma. Con las candidaturas independientes se abre una alternativa democrática para la ciudadanía: la posibilidad de ejercer su derecho a ser votada sin necesidad de estar acompañada por un partido político. En este ensayo se analiza la candidatura independiente en tres momentos: primero, los antecedentes históricos de esta figura y un breve análisis de la misma en otros países; segundo, una descripción de lo que ha sucedido durante los procesos electorales celebrados desde la promulgación de la reforma y; por último, la situación de las candidaturas independientes en el último proceso electoral 2017-2018.

Palabras clave: candidaturas independientes, democracia, ciudadanía, derechos político-electorales, México.

\section{Abstract}

Independent candidacies are a new figure in Mexico due to the fact that they became a tangible reality beginning with the political-electoral reform of 2014. However, they bring with them a series of previous events that made that reform possible. With the independent candidacies a democratic alternative opens for the citizenry: the possibility of exercising the right of being voted without needing a political party. This essay analyzes independent candidacies in three moments: first, the historical background of this figure in Mexico and a brief study of it in other countries; second, a description of what has happened in the elections since the adoption of the figure in 2014; and finally, the situation of independent candidacies in the last elections (20172018).

Key words: independent candidacies, democracy, citizenship, electoral-political rights, Mexico.
\end{abstract}




\section{Introducción}

n los países con sistemas democráticos donde la ciudadanía elige a sus representantes mediante elecciones podemos encontrar, por lo general, una pluralidad de partidos políticos. De éstos emergen las candidaturas que contienden durante los procesos electorales a fin de ocupar un cargo de elección popular. Sin embargo, la baja credibilidad que mantienen los partidos políticos ha abierto el camino a la generación de nuevas opciones para la ciudadanía, que permitan mayor participación, inclusión y pluralidad, derivando en una democracia más completa y enriquecida. ¿Qué sucede entonces con las ciudadanas y los ciudadanos cuya ideología no coincide con aquella de los partidos políticos, pero que desean ejercer su derecho a participar y a ser votados? ¿Son los partidos políticos la única vía para contender por un cargo de elección popular?

Esta figura está reglamentada en países de Latinoamérica como Colombia, Chile, Ecuador, Honduras, Perú, República Dominicana y Venezuela (Gimate-Welsh, 2015), así como en países europeos como Alemania, Francia, Irlanda, y Polonia, además de algunos estados de la Unión Americana (TEPJF, 2013, p. 24-119). Para contender por un cargo de elección popular a través de la figura de candidaturas independientes, los aspirantes deben cubrir una serie de requisitos. Por citar algunos ejemplos, en Chile se necesita tener 21 años para lanzarse por una diputación y 35 años para una senaduría o para la Presidencia (TEPJF, 2013, p. 28); igualmente en Polonia, con la diferencia de que para una senaduría solo se necesita tener 30 años (TEPJF, 2013, p. 36). Respecto de militancia partidista, en Chile el aspirante no puede pertenecer a un partido político al menos nueve meses antes del último día de la presentación de las declaraciones de candidaturas (TEPJF, 2013, p. 29). En Irlanda, se requiere dejar un depósito de 500 euros ante la autoridad electoral si se pretende ir por la vía independiente (TEPJF, 2013, p. 34).

Una vez que estos requisitos sean cumplidos, como regla general, las autoridades electorales solicitan un cierto número de firmas del electorado que dependen de factores como el cargo por el que se desea contender y la población que puede votar en la demarcación en cuestión, por ejemplo, en Alemania se necesitan las firmas de 200 votantes del distrito por el que 
se quiere contender (TEPJF, 2013, p. 27) y en Irlanda, se deben presentar las firmas de al menos 30 personas siendo certificadas por una persona que pueda dar fe pública (TEPJF, 2013, p. 34). Una vez concluida esta etapa, las candidaturas independientes, en su mayoría, son equiparables a los partidos políticos que menos votación hayan obtenido en el último proceso electoral para la repartición tanto de recursos financieros públicos como, en algunos casos, de tiempo en radio y televisión para la difusión de propaganda.

El único caso que difiere del resto en la literatura mencionada es el del estado de Maine en los Estados Unidos de América, ya que el financiamiento de las campañas es privado (donde se establece un tope a las donaciones personales) y solo se exige a las televisoras y estaciones de radio que se les brinde igualdad de oportunidades a las y los candidatos, pero es necesario comprar el tiempo aire para poder difundir los spots de campaña. Por último, vale la pena destacar que, en Alemania, Francia e Irlanda, se estipula que en ciertos casos las y los candidatos, pueden aplicar para un reembolso de los gastos de campaña hechos con dinero privado: en Alemania es 2.80 euros por voto recibido mientras hayan obtenido por lo menos el $10 \%$ de la votación en su distrito (TEPJF, 2013, p. 28), en Francia se debe obtener el 5\% de la votación y se puede recibir el $50 \%$ de los gastos autorizados de campaña, sin haber rebasado el tope de campaña (TEPJF, 2013, p. 33) ${ }^{1}$ y en Irlanda se prevé que el monto máximo de reembolso es de 8,700 euros para las personas que resultaron electas y también para las y los candidatos que obtuvieron al menos una cuarta parte de los votos necesarios para obtener un escaño pero no ganaron (TEPJF, 2013, p. 35).

En México, la figura de candidaturas independientes ha sido reconocida en la Constitución Política de los Estados Unidos Mexicanos (CPEUM) y, por ende, reglamentada también en las normatividades generales, como la

1. Se realizó una revisión a las leyes mencionadas en el artículo citado a fin de corroborar algún cambio en la legislación, donde se encontró un caso: el artículo L 52-11 del código electoral francés que, según el documento citado, hablaba sobre los requisitos para un posible reembolso $(5 \%$ de la votación y un tope de hasta el $50 \%$ del total de los gastos autorizados, sin haber rebasado los topes de gasto de campaña). El artículo actual es el 52-11-1 del código electoral y, aunque el requisito del porcentaje de la votación es el mismo, el tope es el $47.5 \%$ del total de los gastos autorizados, sin haber rebasado el tope de gastos de campaña (IFIJ, 2018). 
Ley General de Instituciones y Procedimientos Electorales (LGIPE) así como en las leyes electorales de las entidades federativas. Al ser reconocidas las candidaturas independientes en los diferentes órdenes de gobierno, esta figura puede entonces participar en los procesos electorales locales y federales para los cargos de elección popular: Presidencia de la República, Senadurías, Diputaciones Federales, Gubernaturas, Ayuntamientos y Diputaciones Locales.

En este ensayo se describirán los hechos históricos previos a que la figura de candidaturas independientes fuera legalmente reconocida en México, para continuar con un análisis de éstas, incluyendo los requisitos que deben cubrir las personas aspirantes a la candidatura independiente para poder aparecer en la boleta, así como su comportamiento durante las elecciones de 2015, 2016 y 2017; se analizarán factores como el número de aspirantes, el número de candidaturas logradas y el número de ganadores, así como la proporción y relación que estos datos guardan con las contiendas electorales en cada proceso. Por último, se abordará el proceso electoral 2017-2018 en México y se presentarán unas breves conclusiones.

\section{La historia de las candidaturas independientes en México}

Las candidaturas independientes fueron contempladas históricamente en la legislación mexicana desde 1810 y hasta 1910, donde se conocían como candidaturas individuales, representadas por ciudadanos prominentes y conocidos. Vázquez Gaspar (citado en Gamboa \& Valdés, 2011, pp. 9-10) refiere que es en 1911 cuando los partidos políticos son reconocidos legalmente y son éstos quienes en aquél entonces dependen de las candidaturas y no a la inversa como es hoy en día. Por otra parte, en 1918 se promulgó la Ley para Elecciones de Poderes Federales (INEHRM, 2018, p. 2) donde, en su artículo 107, señalaba que los candidatos que no dependieran de partidos políticos tendrían los mismos derechos que los candidatos partidistas mientras cumplieran con los requisitos para competir.

Para que la figura de candidaturas independientes lograra rango constitucional en México, le antecedieron diversas situaciones y demandas 
ciudadanas. Si bien a nivel federal no se encontraba legislada esta figura, a nivel local no había restricciones al respecto. Tal fue el caso de Tamaulipas en 1998, donde una ciudadana no registrada ejerció su derecho a ser votada, contendiendo en las elecciones y resultando ganadora obteniendo su constancia por parte de la autoridad electoral (TRIELTAM, 1998; Sebastián, 2013). Los estados de Yucatán y Sonora ya contaban con la figura de candidaturas independientes regulada en sus normativas locales: fue así como en 2007, la Sala Superior del TEPJF reconoció el triunfo de un ciudadano en Yucatán (TEPJF, 2007; Boffil, 2007), quien había sido registrado sin el respaldo de un partido para la elección en un ayuntamiento. Destacan también, a partir de 2001 y hasta el año 2005, siete casos independientes que fueron rechazados al no estar esta figura contemplada en la legislación aplicable en esos años, siendo el de Jorge Castañeda Gutman uno de los más relevantes, el cual llegó hasta la Corte Interamericana de Derechos Humanos².

En 2007, se cierra la posibilidad de registrar candidaturas independientes al establecerse en la CPEUM que postular candidaturas es facultad exclusiva de los partidos políticos. En los años 2012 y 2013, a través de diversos decretos, las candidaturas independientes fueron reconocidas en la CPEUM, pero es a partir de la reforma político-electoral de 2014 que esta figura se vuelve una realidad tangible y viable para los siguientes procesos electorales, estableciéndose en su artículo 35 fracción II, que el registro de candidaturas corresponderá tanto a los partidos políticos como a las y los ciudadanos que lo soliciten, cumpliendo los requisitos determinados por la ley. Además, la LGIPE en su artículo 7, fracción III, determina que los ciudadanos podrán solicitar su registro cumpliendo las calidades descritas en la ley así como los requisitos y condiciones necesarios para esto.

Derivado de lo estipulado en el artículo 357, fracción II, de la misma LGIPE, las legislaturas locales de las entidades federativas incluyeron también en sus normatividades las disposiciones para dar paso a la posibilidad de que la ciudadanía contienda a un cargo de elección popular sin la postulación de un partido político.

2. Para más información sobre este caso, favor de visitar (CIDH, 2008). 


\section{El estado de las candidaturas independientes en México}

Si bien la normatividad ha incluido el derecho de la ciudadanía a ser votada por la vía independiente, existen ciertos requisitos para poder obtener el registro $\mathrm{y}$, de esta forma, poder acceder al financiamiento público para la campaña electoral así como aparecer en la boleta el día de la jornada electoral.

Los institutos electorales, tanto locales como federales, emiten una convocatoria para aspirantes a candidaturas independientes donde se establecen los cargos de elección popular a contender, los requisitos y la documentación a presentar, así como los plazos y porcentaje a obtener de respaldo ciudadano correspondiente.

El artículo 371 de la LGIPE establece los porcentajes de apoyo ciudadano a recabar a nivel federal, son los siguientes:

- Para las candidaturas a la Presidencia de la República, el respaldo ciudadano deberá contener las firmas de por lo menos el 1\% de las personas que estén en la lista nominal de electores con corte al 31 de agosto previo a la elección. Además, este respaldo debe estar integrado por personas de al menos 17 estados del país y que sea por lo menos $1 \%$ de la lista nominal de electores de cada uno de esas 17 entidades.

- Para las candidaturas al Senado de la República, el respaldo debe ser el equivalente al $2 \%$ de la lista nominal correspondiente a la entidad federativa por la cual se quiera contender con corte al 31 de agosto previo a la elección. Asimismo, este respaldo debe de venir de al menos la mitad de distritos electorales que contenga la entidad y significar el $1 \%$ de las listas nominales de cada uno de esos distritos.

- Para las candidaturas a la Cámara de Diputados, el respaldo debe ser el equivalente al $2 \%$ de la lista nominal distrital correspondiente, con corte al 31 de agosto previo a la elección. Además, el respaldo deberá ser de al menos la mitad de las secciones electorales del distrito y significar el 1\% de la lista nominal en cada sección. 
Para las entidades federativas, es menester de las legislaciones locales establecer el porcentaje de respaldo ciudadano requerido para los cargos locales y, generalmente, éstos oscilan entre el $2 \%$ y $2.5 \%$.

Otro aspecto importante a considerar es que los aspirantes a candidaturas independientes deben acreditar la creación de una persona moral constituida en asociación civil, así como su alta ante el Sistema de Administración Tributaria y la apertura de una cuenta bancaria para poder recibir el financiamiento público y privado correspondiente, al tiempo que podrán ser fiscalizados.

Ahora bien, comencemos observando un sencillo análisis en el comportamiento que dicha figura ha presentado en cada proceso electoral posterior a la reforma político electoral 2014, de acuerdo a aquellos ciudadanos que lograron el registro a una candidatura independiente, así como aquellos que lograron la victoria:

\section{Cuadro 1.}

Candidaturas independientes y ganadores, 2014-2017

\begin{tabular}{|c|c|c|c|}
\hline Proceso Electoral & Candidaturas & Ganadores & $\%$ \\
\hline $2014-2015$ & 133 & 6 & $4,51 \%$ \\
\hline \multicolumn{4}{|c|}{ Por Cargo } \\
\hline Diputaciones Federales & 22 & 1 & $4,55 \%$ \\
\hline Gubernaturas & 3 & 1 & $33,33 \%$ \\
\hline Diputaciones Locales & 29 & 1 & $3,45 \%$ \\
\hline Ayuntamientos & 79 & 3 & $3,80 \%$ \\
\hline
\end{tabular}

Número de entidades federativas con proceso electoral: 17

\begin{tabular}{c|c|c|c}
\hline & & & \\
\hline Proceso Electoral & Candidaturas & Ganadores & $\%$ \\
\hline $2015-2016$ & 286 & 10 & $3,49 \%$ \\
\hline
\end{tabular}

Por Cargo

\begin{tabular}{l|c|c|c}
\hline Gubernaturas & 10 & 0 & $0,00 \%$ \\
\hline Diputaciones Locales & 74 & 0 & $0,00 \%$ \\
\hline Ayuntamientos & 202 & 10 & $4,95 \%$ \\
\hline
\end{tabular}




\begin{tabular}{|c|c|c|c|}
\hline \multicolumn{4}{|c|}{ Número de entidades federativas con proceso electoral: 16} \\
\hline Proceso Electoral & Candidaturas & Ganadores & $\%$ \\
\hline $2016-2017$ & 139 & 3 & $2,16 \%$ \\
\hline \multicolumn{4}{|l|}{ Por Cargo } \\
\hline Gubernaturas & 3 & 0 & $0,00 \%$ \\
\hline Diputaciones Locales & 37 & 0 & $0,00 \%$ \\
\hline Ayuntamientos & 99 & 3 & $3,03 \%$ \\
\hline
\end{tabular}

Número de entidades federativas con proceso electoral: 4

Derivado de lo anterior, se desprende el incremento que ha registrado la participación ciudadana para postularse a través de la figura de candidaturas independientes, considerando el número de entidades federativas participando en proceso electoral, fenómeno que no necesariamente se refleja en el porcentaje de ganadores. En 2015, el estado de Nuevo León tuvo el primer candidato independiente ganador para el cargo de gubernatura, logro que no se ha repetido en otras entidades ni procesos. En 2017 vemos que el número de candidaturas independientes registradas es menor a los dos procesos que le anteceden, sin embargo, podemos atribuirlo a que únicamente fueron 4 las entidades federativas con elecciones. Otro aspecto a resaltar es que los ayuntamientos presentan mayor número de ganadores.

En las siguientes tablas ${ }^{3}$, se presenta un análisis más exhaustivo por proceso electoral. La finalidad es observar el comportamiento de las candidaturas independientes respecto de las contiendas, ya que se puede presentar una o más candidaturas independientes registradas para un mismo cargo. Se observan diferentes relaciones que muestran los incrementos porcentuales en la participación a través de las candidaturas independientes en los procesos electorales, utilizando también algunos datos de las tablas anteriores. Con el fin de que las tablas sean mejor comprendidas, se describen a continuación las variables de la primera columna: En primer lugar, se describe el cargo e inmediatamente después, el número de candidaturas

3.Todas las tablas presentadas en este artículo son de elaboración propia con información del Instituto Nacional Electoral y de los diferentes Organismos Públicos Locales Electorales, para lo cual agradezco el valioso apoyo en la recopilación de datos por parte de José Joaquín Suárez Niembro, asesor de esta consejería y de Laura Esquivel Santos, colaboradora. 
independientes registradas; posteriormente, se encuentra el número de candidaturas totales que participaron en las contiendas donde hubo alguna candidatura independiente registrada; en la cuarta fila, se encuentra la proporción de candidaturas independientes registradas con el número total de candidaturas que participaron en contiendas con alguna candidatura independiente. Posteriormente encontramos el número de candidaturas independientes ganadoras y luego la proporción de ganadores independientes con el número total de candidaturas que participaron en las contiendas donde hubo alguna candidatura independiente. Debajo de la línea punteada se describen variables a nivel de contienda, tales como el número de contiendas donde compitieron independientes; el número de contiendas totales en dicho proceso; la proporción de las contiendas con independientes con el total de contiendas; la proporción de contiendas ganadas por independientes con las contiendas totales y; por último, la proporción de contiendas ganadas por independientes con las contiendas donde hubo alguna candidatura independiente.

\section{Cuadro 2.}

Comportamiento de las candidaturas independientes 2014-2015

\begin{tabular}{l|r|r|r|r|c}
\multicolumn{1}{c|}{ Cargo } & $\begin{array}{c}\text { Diputados } \\
\text { Federales }\end{array}$ & $\begin{array}{c}\text { Guberna- } \\
\text { turas }\end{array}$ & $\begin{array}{c}\text { Diputa- } \\
\text { ciones } \\
\text { Locales }\end{array}$ & $\begin{array}{c}\text { Ayunta- } \\
\text { mientos }\end{array}$ & Total \\
\hline $\begin{array}{l}\text { Candidaturas indepen- } \\
\text { dientes registradas }\end{array}$ & 22 & 3 & 29 & 79 & 133 \\
\hline $\begin{array}{l}\text { \# Candidaturas en } \\
\text { contienda con indepen- } \\
\text { dientes }\end{array}$ & 203 & 25 & 182 & 625 & 1035 \\
\hline $\begin{array}{l}\text { \% Candidaturas Inde- } \\
\text { pendientes }\end{array}$ & $10,84 \%$ & $12,00 \%$ & $15,93 \%$ & $12,64 \%$ & $12,85 \%$ \\
\hline Ganadores & 1 & 1 & 1 & 3 & 6 \\
\hline $\begin{array}{l}\text { Ganadores / \# de can- } \\
\text { didaturas en contienda }\end{array}$ & $0,49 \%$ & $4,00 \%$ & $0,55 \%$ & $0,48 \%$ & $0,58 \%$ \\
\hline
\end{tabular}




\begin{tabular}{l|r|r|r|r|r}
\hline $\begin{array}{l}\text { Contiendas donde } \\
\text { compitieron candidatu- } \\
\text { ras independientes }\end{array}$ & 21 & 3 & 28 & 73 & 125 \\
\hline Contiendas Totales & 300 & 9 & 387 & 1009 & 1705 \\
\hline $\begin{array}{l}\text { Contiendas con candi- } \\
\text { daturas independientes } \\
/ \text { Contiendas Totales }\end{array}$ & $7,00 \%$ & $33,33 \%$ & $7,24 \%$ & $7,23 \%$ & $7,33 \%$ \\
\hline $\begin{array}{l}\text { Ganadores / Contien- } \\
\text { das totales }\end{array}$ & $0,33 \%$ & $11,11 \%$ & $0,26 \%$ & $0,30 \%$ & $0,35 \%$ \\
\hline $\begin{array}{l}\text { Ganadores / Contien- } \\
\text { das con candidaturas } \\
\text { independientes }\end{array}$ & $0,48 \%$ & $33,33 \%$ & $3,57 \%$ & $4,11 \%$ & $4,80 \%$ \\
\end{tabular}

\section{Cuadro 3.}

Comportamiento de las candidaturas independientes 2015-2016

Proceso Electoral 2015-2016

\begin{tabular}{l|c|c|c|c}
\hline \multicolumn{1}{c|}{ Cargo } & Gubernaturas & $\begin{array}{c}\text { Diputacio- } \\
\text { nes Locales }\end{array}$ & Ayuntamientos & Total \\
\hline $\begin{array}{l}\text { Candidaturas } \\
\text { independientes } \\
\text { registradas }\end{array}$ & 10 & 74 & 202 & 286 \\
\hline $\begin{array}{l}\text { \# Candidaturas en } \\
\text { contienda con inde- } \\
\text { pendientes }\end{array}$ & 61 & 530 & 1247 & 1838 \\
\hline $\begin{array}{l}\text { \% Candidaturas } \\
\text { Independientes }\end{array}$ & $16,39 \%$ & $13,96 \%$ & $16,20 \%$ & $15,56 \%$ \\
\hline \begin{tabular}{l} 
Ganadores \\
\hline $\begin{array}{l}\text { Ganadores / \# } \\
\text { Candidaturas en } \\
\text { contienda }\end{array}$
\end{tabular}$\quad 0,00 \%$ & $0,00 \%$ & $10,80 \%$ & $0,54 \%$ \\
\hline $\begin{array}{l}\text { Contiendas donde } \\
\text { compitieron candida- } \\
\text { turas independientes }\end{array}$ & 9 & 56 & 142 & 207 \\
\hline \begin{tabular}{l} 
Contiendas Totales \\
\hline
\end{tabular} & 13 & 239 & 968 & 1220 \\
\hline
\end{tabular}




\begin{tabular}{l|c|c|c|c}
\hline $\begin{array}{l}\text { Contiendas con can- } \\
\text { didaturas indepen- } \\
\text { dientes / Contiendas } \\
\text { Totales }\end{array}$ & $69,23 \%$ & $23,43 \%$ & $14,67 \%$ & $16,97 \%$ \\
\hline $\begin{array}{l}\text { Ganadores / Contien- } \\
\text { das totales }\end{array}$ & $0,00 \%$ & $0,00 \%$ & $1,03 \%$ & $0,82 \%$ \\
\hline $\begin{array}{l}\text { Ganadores / Contien- } \\
\text { das con candidaturas } \\
\text { independientes }\end{array}$ & $0,00 \%$ & $0,00 \%$ & $7,04 \%$ & $4,83 \%$ \\
\end{tabular}

\section{Cuadro 4.}

Comportamiento de las candidaturas independientes 2016-2017

Proceso Electoral 2016-2017

\begin{tabular}{|c|c|c|c|c|}
\hline Cargo & Gubernaturas & $\begin{array}{c}\text { Diputacio- } \\
\text { nes Locales }\end{array}$ & Ayuntamientos & Total \\
\hline $\begin{array}{l}\text { Candidaturas indepen- } \\
\text { dientes registradas }\end{array}$ & 3 & 37 & 99 & 139 \\
\hline $\begin{array}{l}\text { \# de candidaturas en } \\
\text { contienda con inde- } \\
\text { pendientes }\end{array}$ & 13 & 186 & 471 & 670 \\
\hline $\begin{array}{l}\% \text { Candidaturas Inde- } \\
\text { pendientes }\end{array}$ & $23,08 \%$ & $19,89 \%$ & $21,02 \%$ & $20,75 \%$ \\
\hline Ganadores & 0 & 0 & 3 & 3 \\
\hline $\begin{array}{l}\text { Ganadores / \# de can- } \\
\text { didaturas en contienda }\end{array}$ & $0,00 \%$ & $0,00 \%$ & $0,64 \%$ & $0,45 \%$ \\
\hline $\begin{array}{l}\text { Contiendas donde } \\
\text { compitieron candida- } \\
\text { turas independientes }\end{array}$ & 2 & 21 & 77 & 100 \\
\hline Contiendas Totales & 3 & 34 & 270 & 307 \\
\hline $\begin{array}{l}\text { Contiendas con } \\
\text { candidaturas indepen- } \\
\text { dientes / Contiendas } \\
\text { Totales }\end{array}$ & $66,67 \%$ & $61,76 \%$ & $28,52 \%$ & $32,57 \%$ \\
\hline $\begin{array}{l}\text { Ganadores / Contien- } \\
\text { das totales }\end{array}$ & $0,00 \%$ & $0,00 \%$ & $1,11 \%$ & $0,98 \%$ \\
\hline $\begin{array}{l}\text { Ganadores / Contien- } \\
\text { das con candidaturas } \\
\text { independientes }\end{array}$ & $0,00 \%$ & $0,00 \%$ & $3,90 \%$ & $3,00 \%$ \\
\hline
\end{tabular}


Como se puede observar existe un incremento en el porcentaje de candidaturas independientes a lo largo de los tres procesos reflejados en las tablas $(12.85 \%$ en $2014-2015,15.56 \%$ en $2015-2016$ y $20.75 \%$ en $2016-2017$ ), así como en la proporción de contiendas con independientes respecto a las contiendas totales (7.33\% en 2014-2015, $16.97 \%$ en $2015-2016$ y $32.57 \%$ en $2016-2017)$. En cuanto a ganadores, no se observa una relación directa entre el número de participantes y el número de ganadores; en otras palabras, el que haya más candidaturas independientes no lleva necesariamente a un aumento de personas ganadoras: por un lado, la proporción de ganadores independientes respecto al número de candidaturas en contienda con independientes ha disminuido (0.58\% en $2014-2015,0.54 \%$ en $2015-2016,0.45 \%$ en $2016-2017$ ); por otro lado, comparando el número de ganadores independientes y las contiendas, tanto totales como aquellas en las que participaron independientes, por lo general aumentó $(0.35 \%$ y $4.80 \%$ en $2014-2015$, $0.82 \%$ y $4.83 \%$ en 2015 2016, 0.98\% y 3\% en 2016-2017). Cabe mencionar nuevamente que en 2017 únicamente cuatro entidades tuvieron proceso electoral y esto pudo ser factor en los diferentes datos obtenidos.

\section{El estado de las candidaturas independientes en el proceso electoral 2017-2018}

El proceso electoral 2017-2018 fue la segunda vez que la figura de candidaturas independientes estuvo presente en la contienda para cargos federales. Cabe mencionar que, posterior a los procesos electorales antes descritos, algunas legislaciones locales presentaron reformas, tal fue el caso de Querétaro, donde el porcentaje de respaldo ciudadano requerido bajó del $2.5 \%$ al $2 \%$. Igualmente, la forma de obtener el respaldo ciudadano ha sufrido modificaciones: originalmente consistía únicamente de un formato en papel donde la ciudadanía llenaba sus datos y plasmaba su firma, además de presentar su credencial de elector para otorgar su respaldo a algún aspirante a candidatura independiente; no obstante, para las elecciones federales del proceso electoral 2018, se implementó el uso de nuevas tecnologías por medio de una app donde los aspirantes a candidaturas independientes tomaban la foto de la credencial de elector de la ciudadanía que deseaba otorgar su 
respaldo y la firma era de manera digital. En algunas entidades federativas, como es el caso de Querétaro, la legislación local también contempla el uso del formato en papel, por lo cual permanecieron ambas opciones.

El proceso electoral 2017-2018 en México ha sido el más grande y complejo en la historia moderna de nuestro país: 30 de 32 entidades federativas tuvieron elecciones locales concurrentes además de las elecciones federales donde se eligió a la Presidencia de la República y a las dos cámaras del Congreso de la Unión. Este proceso no fue la excepción para que la ciudadanía tuviese la oportunidad de participar mediante la figura de candidaturas independientes. En la siguiente tabla, se muestra el comportamiento a cargos federales que presentó dicha figura:

\section{Cuadro 5.}

Proceso de registro de las candidaturas independientes 2017-2018

\begin{tabular}{l|c|c|c|c|c}
$\begin{array}{c}\text { Proceso Electo- } \\
\text { ral Federal } \\
\mathbf{2 0 1 7}-\mathbf{2 0 1 8}\end{array}$ & $\begin{array}{c}\text { Manifes- } \\
\text { tación de } \\
\text { intención } \\
\text { para ser } \\
\text { aspirantes }\end{array}$ & $\begin{array}{c}\text { Número de } \\
\text { aspirantes } \\
\text { al iniciar } \\
\text { captación } \\
\text { de respaldo } \\
\text { ciudadano }\end{array}$ & $\begin{array}{c}\text { Aspirantes } \\
\text { con proceso } \\
\text { vigente } \\
\text { durante la } \\
\text { captación }\end{array}$ & $\begin{array}{c}\text { Aspirantes } \\
\text { que preli- } \\
\text { minarmen- } \\
\text { te lograron } \\
\text { el respaldo } \\
\text { ciudadano }\end{array}$ & $\begin{array}{c}\text { Aspiran- } \\
\text { tes que } \\
\text { lograron } \\
\text { el respaldo } \\
\text { ciudadano }\end{array}$ \\
\hline $\begin{array}{l}\text { Diputaciones } \\
\text { Federales }\end{array}$ & 240 & 187 & 143 & 64 & $40^{4}$ \\
\hline Senadurías & 78 & 55 & 45 & 9 & 7 \\
\hline $\begin{array}{l}\text { Presidencia de la } \\
\text { República }\end{array}$ & 87 & 48 & 46 & 3 & 2 \\
\hline Total & 405 & 290 & 234 & 76 & 49
\end{tabular}

De la tabla se desprende que, de 405 personas que inicialmente presentaron una manifestación de intención para ser aspirantes a candidaturas independientes, 290 presentaron los requisitos y comenzaron con la etapa para la obtención de

4. Sin embargo, solo 38 aparecieron en la boleta ya que, por diversos motivos, dos no cumplieron con alguno de los demás requisitos 
firmas correspondientes al respaldo ciudadano; 234 personas continuaron con el proceso mientras que 56 de ellas no lo concluyeron por distintas razones que pueden ser desde declinar su intención, sumarse a alguna propuesta partidista o a otro aspirante a candidatura independiente, entre otras. Preliminarmente, 76 personas lograron el respaldo ciudadano requerido de acuerdo a la candidatura deseada, sin embargo, y posterior a un análisis que llevó a cabo el INE a fin de corroborar que las firmas presentadas fueran válidas ${ }^{5}, 49$ personas lograron obtener el respaldo ciudadano para poder registrarse a la candidatura deseada y aparecieron en la boleta. Entre ellos, destacan las primeras candidaturas independientes a la Presidencia de la República, Margarita Zavala y Jaime Rodríguez Calderón, gobernador independiente del estado de Nuevo León.

En la siguiente tabla, al igual que en el apartado anterior, se expone una vista general de la figura de las candidaturas independientes en el proceso electoral 2017-2018.

\section{Cuadro 6.}

Candidaturas independientes 2017-2018

\begin{tabular}{l|c|c|c}
\multirow{2}{*}{$\begin{array}{c}\text { Proceso Electoral } \\
\mathbf{2 0 1 7}-\mathbf{2 0 1 8}\end{array}$} & Candidaturas & Ganadores & \% \\
\cline { 2 - 4 } & $\mathbf{6 2 8}$ & $\mathbf{3 0}$ & $\mathbf{4 . 7 8 \%}$ \\
\hline \multicolumn{2}{|c}{ Por Cargo } \\
\hline Presidencia & 2 & 0 & $0.00 \%$ \\
\hline Senadores & 7 & 0 & $0.00 \%$ \\
\hline $\begin{array}{l}\text { Diputaciones Fede- } \\
\text { rales }\end{array}$ & 38 & 0 & $0.00 \%$ \\
\hline Gubernaturas & 4 & 0 & $0.00 \%$ \\
\hline Diputaciones Locales & 159 & 30 & $0.00 \%$ \\
\hline Ayuntamientos & 418 & $0.18 \%$ \\
\hline
\end{tabular}

Número de entidades federativas con proceso electoral: 30

5. Es decir, que correspondan a la demarcación a la cual se pretende contender, que no se haya duplicado el respaldo a dos o más aspirantes, que sea la credencial de elector el documento que avala el respaldo de la ciudadanía, entre otros. 
Lo que se desprende de esta tabla es que el número de candidaturas independientes y la proporción de ganadores ha aumentado, comparándolo con los procesos electorales pasados, siendo esto un signo de que la figura de la candidatura independiente es bien recibida por la población. Sin embargo, también se leen dos cosas importantes: la primera, que el aumento de candidaturas independientes se puede deber a que las elecciones del 1 de julio fueron las más grandes en la historia del país; y la segunda, que las y los candidatos independientes únicamente lograron ganar ayuntamientos. Este último fenómeno puede deberse a diferentes razones, como el arraigo que la candidatura independiente tiene en su Ayuntamiento, ya que es normalmente conocida por la ciudadanía y hay una cercanía con ella.

\section{Cuadro 7.}

Comportamiento de las candidaturas independientes 2017-2018

Proceso Electoral 2017-2018

\begin{tabular}{l|c|c|c|c|c|c|c}
\hline \multicolumn{1}{c|}{ Cargo } & $\begin{array}{c}\text { Presiden- } \\
\text { cia }\end{array}$ & $\begin{array}{c}\text { Sena- } \\
\text { duría }\end{array}$ & $\begin{array}{c}\text { Dipu- } \\
\text { tación } \\
\text { Federal }\end{array}$ & $\begin{array}{c}\text { Guber- } \\
\text { natura }\end{array}$ & $\begin{array}{c}\text { Dipu- } \\
\text { tación } \\
\text { Local }\end{array}$ & $\begin{array}{c}\text { Ayun- } \\
\text { tamien- } \\
\text { to }\end{array}$ & Total \\
\hline $\begin{array}{l}\text { Candidaturas } \\
\text { independientes } \\
\text { registradas }\end{array}$ & 2 & 7 & 38 & 4 & 159 & 418 & 628 \\
\hline $\begin{array}{l}\text { \# Candidaturas } \\
\text { en contienda } \\
\text { con indepen- } \\
\text { dientes }\end{array}$ & 5 & 35 & 230 & 25 & 1010 & 2456 & 3761 \\
\hline $\begin{array}{l}\text { Candidaturas } \\
\text { independientes / } \\
\text { \# de candidatu- } \\
\text { ras en contienda }\end{array}$ & $40.00 \%$ & $20.00 \%$ & $16.52 \%$ & $16.00 \%$ & $15.74 \%$ & $17.02 \%$ & $16.70 \%$ \\
\hline \begin{tabular}{l} 
Ganadores \\
\hline $\begin{array}{l}\text { Ganadores / \# } \\
\text { de candidaturas } \\
\text { en contienda }\end{array}$
\end{tabular} & $0.00 \%$ & $0.00 \%$ & $0.00 \%$ & $0.00 \%$ & $0.00 \%$ & $1.22 \%$ & $0.80 \%$ \\
\hline $\begin{array}{l}\text { Contiendas don- } \\
\text { de compitieron } \\
\text { candidaturas } \\
\text { independientes }\end{array}$ & 1 & 7 & 37 & 4 & 130 & 332 & 511 \\
\hline
\end{tabular}




\begin{tabular}{l|c|c|c|c|c|c|c}
\hline $\begin{array}{l}\text { Contiendas } \\
\text { Totales }\end{array}$ & 1 & 32 & 300 & 9 & 585 & 1636 & $2563^{6}$ \\
\hline $\begin{array}{l}\text { Contiendas con } \\
\text { candidaturas } \\
\text { independientes } \\
/ \text { Contiendas } \\
\text { Totales }\end{array}$ & $100.00 \%$ & $21.88 \%$ & $12.33 \%$ & $44.44 \%$ & $22.22 \%$ & $20.29 \%$ & $19.94 \%$ \\
\hline $\begin{array}{l}\text { Ganadores / } \\
\text { Contiendas } \\
\text { totales }\end{array}$ & $0.00 \%$ & $0.00 \%$ & $0.00 \%$ & $0.00 \%$ & $0.00 \%$ & $1.83 \%$ & $1.17 \%$ \\
\hline $\begin{array}{l}\text { Ganadores / } \\
\text { Contiendas con } \\
\text { candidaturas } \\
\text { independientes }\end{array}$ & $0.00 \%$ & $0.00 \%$ & $0.00 \%$ & $0.00 \%$ & $0.00 \%$ & $9.04 \%$ & $5.87 \%$ \\
\hline
\end{tabular}

Se observa un decremento en el porcentaje de candidaturas independientes en comparación con el proceso electoral anterior (20.75\% en 2016-2017 y $12.85 \%$ en $2017-2018$ ), así como en la proporción de contiendas con independientes respecto a las contiendas totales $(32.57 \%$ en $2016-2017$ a $7.33 \%$ en 2017-2018) pero esto se puede deber a que, al ser las elecciones más grandes en la historia del país, hubo más contiendas $(2,563)$ que en procesos anteriores (307 en 2016-2017). La proporción de ganadores independientes respecto al número de candidaturas en contienda con independientes aumentó ( $0.45 \%$ en $2016-2017$ a $0.80 \%$ en $2017-2018)$ y la proporción entre el número de ganadores independientes y las contiendas, tanto totales como aquellas en las que participaron independientes, también aumentó (0.98\% y 3\% en 20162017 a $1.17 \%$ y $5.87 \%$ en $2017-2018$ ), lo cual puede significar que la figura ya se ha afianzado entre la ciudadanía como una nueva opción viable. Por supuesto, estas son apreciaciones que se desprenden del estudio realizado; digno de análisis y de debate son este y los siguientes procesos electorales y su comportamiento.

6. Los cargos a elegir para esta elección fueron más de 3,400. Sin embargo, una vez que se sustraen los cargos de representación proporcional, los cargos a concejalías y las senadurías por primera minoría, además de solo asignar una contienda por estado para el Senado, se llega a las 2,563 contiendas. 


\section{Conclusiones}

Las candidaturas independientes han recorrido un largo camino para poder llegar a ser una realidad constitucional en México y han sido un elemento de total relevancia para la democracia en nuestro país. Hay claros ejemplos en democracias contemporáneas donde no es necesario contar con el apoyo de un partido político para poder ejercer el derecho a contender por la vía independiente. Paulatinamente, como se pudo ver en las distintas tablas, hemos adoptado esta figura en México. Es importante destacar el aumento en el número de candidaturas independientes a través de los diferentes procesos electorales, aunque esto no necesariamente se haya traducido en más candidaturas ganadoras.

En el proceso electoral más grande en la historia de nuestro país, se ha dado cuenta de un número considerable de candidaturas independientes, entre ellas el de las primeras candidaturas independientes para la Presidencia de la República. Además, el uso de nuevas tecnologías ha sido otro elemento encausado como una herramienta adicional de apoyo para la obtención del respaldo ciudadano. La candidatura independiente es una figura que ha presentado cambios normativos desde su inclusión constitucional hasta el día de hoy y que seguramente presentará más a medida que pase el tiempo, derivado de distintos factores perfectibles que la puesta en práctica ha arrojado. Las candidaturas independientes constituyen, cada vez más, una opción viable para quien desea aparecer en la boleta electoral sin el respaldo de partido político alguno, además de ofrecer más opciones a la ciudadanía que se presenta a votar en las jornadas electorales, dando paso a una mayor pluralidad e inclusión en la democracia de nuestro país.

\section{Referencias}

Báez, C., \& Tello, M. (2015).”El fenómeno de las candidaturas independientes en México. Análisis de su implementación y primeros resultados en el proceso electoral 2015". Revista Mexicana De Derecho Electoral, 1(7), 237-264. doi:10.22201/iij.24487910e.2015.7.10091 
Boffil, L. A. (2007, Julio 2). Municipio yucateco tiene al primer edil independiente de México en 61 años. La Jornada. Recuperado de http://www.jornada.com.mx/2007/07/02/index. php? section $=$ estados $\&$ article $=038 \mathrm{n} 1$ est

Comisión Interamericana de Derechos Humanos (CIDH). (2007). "Demanda ante la Corte Interamericana de Derechos Humanos en el caso de Jorge Castañeda Gutman (Caso 12.535) contra los Estados Unidos Mexicanos". Recuperado de http://www.cidh.org/demandas/12.535\%20 Jorge $\% 20$ Castaneda $\% 20$ Gutman $\% 20$ Mexico $\% 2021 \% 20$ marzo $\% 20$ 2007\%20ESP.pdf

Gamboa, C., \& Valdés, S. (2011). Candidaturas Independientes. Estudio conceptual de antecedentes, jurisprudencia, iniciativas presentadas en la LX y LXI Legislaturas, de Derecho comparado y opiniones especializadas. Recuperado de http://www.diputados.gob.mx/sedia/sia/ spi/SAPI-ISS-09-11.pdf

Gimate-Welsh, A. S. (2015). Candidaturas Independientes. México y América Latina. Recuperado de http://csh.izt.uam.mx/sistemadivisional/SDIP/ proyectos/archivos_rpi/pel_18349_784_Cand_Indep_Mexico_Am_ Latina_30_junio_2014-Salamanca.pdf

Constitución Política de los Estados Unidos Mexicanos [Const.]. (1917). Recuperada de http://www.diputados.gob.mx/LeyesBiblio/ pdf/1_150917.pdf

Congreso de la Unión. (23 de mayo de 2014). Ley General de Instituciones y Procedimientos Electorales. Recuperada de http://www.diputados.gob. mx/LeyesBiblio/pdf/LGIPE_270117.pdf

Institut Français d'Information Juridique. (2018). Code Électoral. Recuperado de http://codes.droit.org/CodV3/electoral.pdf 
Instituto Nacional de Estudios Históricos de las Revoluciones de México (INEHRM). (2018). Ley para la Elección de Poderes Federales, 2 de julio de 1918. Recuperado de http://www.inehrm.gob.mx/work/models/ inehrm/Resource/668/1/images/Doc1.pdf

Sebastián, Á. M. (2013). "Nota informativa sobre el caso de la C. María del Rosario Elizondo Salinas, electa presidenta municipal de Santander Jiménez, Tamaulipas, como candidata no registrada en 1998". Recuperado de http://portales.te.gob.mx/candidaturas/sites/default/ files/NOTA \%20INFORMATIVA\%20SOBRE\%20CASO $\% 20$ DE $\% 20$ CANDIDATA\%20NO\%20REGISTRADA_0.pdf

Tribunal Electoral del Estado de Tamaulipas (TRIELTAM). (1998). S2ARIN-076/1998.

Tribunal Electoral del Poder Judicial de la Federación (TEPJF), Sala Superior. (25 de octubre de 2001). SUP-JDC-037/2001 [Mgdo. José de Jesús Orozco Henríquez]. Recuperado de http://portal.te.gob.mx/colecciones/ sentencias/html/SUP/2001/JDC/SUP-JDC-00037-2001.htm

Tribunal Electoral del Poder Judicial de la Federación (TEPJF), Sala Superior. (20 de junio de 2007). SUP-JRC-86/2007 [M.P. Flavio Galván Rivera]. Recuperado de http://portal.te.gob.mx/colecciones/sentencias/html/ SUP/2007/JRC/SUP-JRC-00086-2007.htm

Tribunal Electoral del Poder Judicial de la Federación (TEPJF). (2013). Dossier sobre candidaturas independientes. Recuperado de http://www. te.gob.mx/ccje/Archivos/Dossier_Candidaturas.pdf 